\title{
ROLE OF WOMEN IN TOURISM
}

\section{Dilip $M R^{*}$}

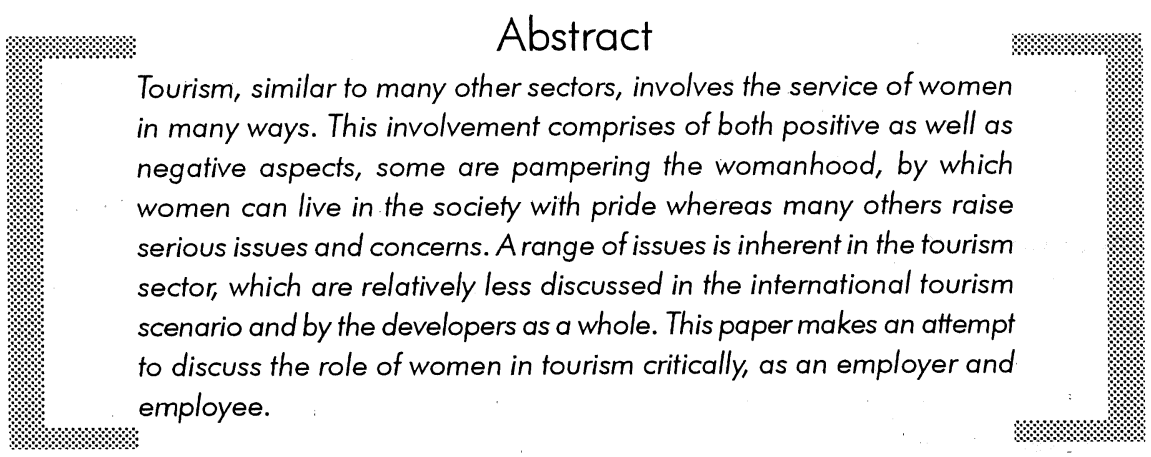

\section{Introduction}

"Women are important producers in the tourism industry and their growing involvement in the paid labour markets of many countries is also increasing their role as tourism consumers" (Sinclair, 1998)

Tourism has grown in to one of the largest industries in the world (WTO, 2005), particularly in terms of employment. Already the sector has generated millions of employment opportunities (Cooper, et.al 1993). Travel and tourism industry is an

* Head, Department of Tourism, Kerala Institute Of Tourism and Travel Studies, Trivandrum. 
amalgam of industries. But many studies have pointed out that women are yet to get due share in the case of employment. The tourism industry seems to be a particularly good 'contender' for engaging in efforts towards the advancement of women (Dutta, 2000). In this article, secondary resources are mainly used for the discussion. Primary data is also collected to discuss the local scenario (Kerala) in a limited manner.

\section{Women and Tourism: Employment Scenario}

Tourism is considered a very effective tool for the elimination of poverty and employment generation. As mentioned earlier, though it has grown in to one of the largest industries in the world in terms of employment generation, still tourism suffers from men's control over women's labour to a large extent and that results in women's employment in low wages and continued dependence upon men. Many other sectors are also not different from this, but tourism is considered as an industry and a process of the modern world; and also the gender disparity between women and men in tourism and the consequences thereupon are worse.

Many statistics on women employment from different regions of the world claims high share for women, even up to 45 to 50 percent. For example the reports of ILO and UNDP. An ILO and UNDP study reports reveal the following $(I L O, 1998)$ :

The general picture suggests that the tourism industry seems to be a particularly important sector for women (46\% of the workforce are women) as their percentage of employment in most countries is higher than in the workforce in general (34 - $40 \%$ are women). Examining the occupations being particularly relevant in the tourism sector, one can see that more than $90 \%$ of people working in catering \& lodging, as waitresses, bartenders, maids, babysitters, cleaners, housekeeping helpers, launderers, dry-cleaners, and the like, are women. The US national restaurant Association report in 2003 show that more then $40 \%$ of American adults have worked in a restaurant and the share of female employees is $44 \%$. Women around the world have achieved higher levels of education than ever before and today represent more than $40 \%$ of the global workforce. Yet their share of management positions remains unacceptably low, with just a tiny proportion succeeding in breaking through the "glass ceiling". There are numerous interlinked factors, which help to maintain gender segregation of the labour market. Among them are gender stereotyping, traditional gender roles and gender identity - women are seen as being suitable for certain occupations and they see themselves as suitable. In addition, traditional gender roles assign to women the main responsibilities for raising children, caring for the elderly, and doing household work. Thus, women are offen forced to choose casual labour, part-time and seasonal employment. (Sunita- Sengupta, 2003), 
Low payment is an issue associated with women employment in tourism. The proportion of wages of women to that of men is considerably less, particularly the part time and temporary employees. Payment to women involved in same jobs as men do, are sometimes lesser than men (Hemmati M, 2000). This is a clear case of inequality and gender discrimination. In such cases either women are ignorant of their rights or they are barred from raising their rights and forming associations to act against it.

Tourism is featured with gendered employment activities. For example, cooking, cleaning, serving, handicraft, etc., Women in the formal sector of tourism were relegated to relatively low skill and low paying or stereotypical jobs. In the international tourism employment scenario, some studies have shown that women have good share in the overall employment, even more than 45 percent. But, further analysis reveals that majority of such jobs for women are in the extreme bottom level of the employment pyramid.

Part time as well as low paid jobs is the feature there for the women in tourism. Largest share of the women employment are in the low level jobs. In the higher levels, women's share is very low, where men dominate. For example in the restaurant industry, women are more employed as helps, cooks (not chefs), and waitresses, not as well paid chefs as well as employees get more incentives, tips, from the customers. In travel agencies, women have considerably higher share. But still majority are at the operational level and in the front desks where attractiveness is required to satisfy customers (Sinclair, 1998; UNDP, 1995).

A UNDP study revelations stands a testimony to the above.

"Within tourism industry, women are concentrated in low skilled and low paid occupations, they are being objectified as part of the tourism "package" and they can have their traditional roles perpetuated within an industry that feeds on uncomplicated images. In less direct ways too, women will be among those most adversely affected by tourism development-eg. by scarcity of fresh water." (UNDP, 1995)

Informal sector is the section of tourism industry that has relatively higher female involvement. There also, the jobs they are involved with are low paid as well as low skilled, say for instance jobs like washing clothes, petty trading, cooking, etc.

Women also do not get benefits as their counterparts as employees in the tourism sector. Absence of human resource development programmes is another issue with regard to employment for women in tourism. 
In some areas of tourism, in some regions, male domination is almost cent percent in the case of employment in the tourism sector. Guiding is an example of it. A sample survey conducted among the tour guides in Kerala reveals that, women are yet to consider guiding a career option for them in Kerala due to its inherent difficulties and socio cultural aspects. Women's share in guiding is negligible in Kerala. Number of reputed guides in Kerala is just a few, four or five only, the study reveals. But the situation is better in metros, particularly Mumbai, where ladies treat guiding a career, mainly as part time and is restricted mainly to short-term trips, not for long haul tours. In Kerala due to negative mindset women find it very difficult to consider guiding as a career suitable for them. The society is still not ready to accept guiding as a suitable career for women. Also, women are supposed to be vulnerable to more difficulties during the course of the journey as a guide. For instance, if the vehicle they travel breaks down in the night, the tourists in the group will get irritated and the guide will become responsible for the situation. If it is a lady, she may face difficulty at this juncture. But yet women can come to this sector, and can act as very efficient guides, particularly for the short trips, the study reveals.

Women employment in tourism brings in increased benefits in general. Various studies have shown that women, who are relatively in the lower strata of the society, who produce handicrafts that are sold to tourists gained a sort of power within the family, though not in the society as a whole. Also, women play as a key role in cultural interaction with tourists, mainly by disseminating knowledge on traditional cultural values. Here, women gain status and prestige and independence to a certain extent.

Women are sometimes part of the businesses in tourism. Women participation as entrepreneurs in business is mainly seen in tiny, small and medium businesses. Bed and breakfast establishments, farmhouses, home stays, are the components of accommodation sector, where women entrepreneurship is predominantly seen and experienced. Women alone own and manage establishments, which give them enough power and security. But, in some cases women's participation in above such businesses are seen as extension of their domestic roles and activities, but on the contrary, it has so much of relevance and importance (Sinclair, 1998; Hemmati $M, 2000)$

\section{"Sexual Sell"}

Sexuality is an important factor in tourism. It is an accepted fact that women are being shown in a stereotypical way in marketing and promotion activities (Hemmati $M, 2000$ ). Women are to some extent sexual and exotic markers in the tourism brochures. Researchers have also argued that generally, women in tour/destination/ 
NTO brochures and websites are represented in terms of sexuality. An analysis using the brochures of 20 Ayurveda centers has revealed that none of the brochure is seen without a sexual appealing women's posture.

Hospitality and Tourism Sector is considered as the most negative and prominent example of sexual objectification of women working in the industry. Sexual harassment is an important issue faced by women in these sectors. In many occasions, "women have to play along with sexual harassment by customers as well as male bosses. Women are expected to dress in an attractive manner to look young, slim, etc". Also women face high risk of sexual harassment and sexual exploitation. Their chances for showing dissent are almost nil in this sector, if they face issues. The role of tourism in increased women trafficking, prostitution and women abuse is very high and has been a seriously debated issue world over (Equations, 1998).

Sex Tourism is the worst of all the issues associated with women in tourism. In it, women are used, as a commodity for the satisfaction of men's coarse needs. This issue has been debated widely in the international scenario and hence it doesn't need any introduction. Some destinations, while they promoted tourism blindly, created pathways for sex tourism (Rao,. 1997) Those destinations are still struggling with the image of a sexual tourism destination, which is very difficult to remove. The social and cultural issues inherent with sexual tourism are many, including spread of diseases like AIDS.

The developing and undeveloped countries, which developed tourism in a haphazard manner and facing the problem of sex tourism, have been struggling with the image as a sex tourism destination. The increasing sex trade in connection with tourism is opening all doors for poor and ignorant girls to be trapped. Girls are reported to be forced to work in bars, nightclubs, and similar establishments where they are exposed to all sorts of sexual abuse. India, due to many reasons is yet be identified as sex tourism destination, barring a few places in the country which are encouraging sex trade along with tourism (Haladi, 2008).

In certain cases, especially in the accommodation sector, the womanhood is being used as a commodity, rather than an individual employment unit equal to man. For instance in the context of leisure parks, "Managers require female employees to dress in a stereotypically feminine fashion and to respond positively to sexual innuendos as part of their interaction with male consumers. Thus, gendered and sexualized modes of behaviors and appearance are often demanded and supplied as part of tourism transactions".

The evolution of sustainable tourism development principles and strategies flaws such development and planners, policy makers, promoters are relatively more 
conscious about the negative impacts of promotion of destination image in terms of sexuality. The credit for this transformation has to be attributed to the increasing international propaganda against sex tourism by some tourism agencies and associations.

In some destinations, local youngsters are involved in different activities, particularly in beaches and similar recreational centres, including sexual activities with women tourists, who to a great extent invite disapproval of the local community. In such cases, women tourists are reported to be gaining "power" through them by offering money as well as other resources. The social issues as part of this are not easy to be neglected as far as some communities are concerned (Sinclair, 1998; Rao, 1997).

"The enclave tourism" raises fear among women to work in the tourism sector since they are not aware of what is happening inside. Society also, to a great extent, discourages women to take part in tourism activities in a destination.

Reports are also there that the girls belonging to a few Indian tourist destinations are finding it difficult to get married since the kind of tourism activities over there brought bad reputation to them. When the destination has an image highlighted by prostitution, this will affect the local community and that will even extend to a situation by which the middle class may be moved away from there to some other places (Equations, 1998).

\section{How to overcome}

Tourism is undoubtedly the industry of the modern world. It is highly labour intensive sector and its employment generation capabilities make it the largest industry in the world.

The problems faced by women in this industry were a less discussed topic at the international level. Women can work as equal as men in almost all kinds of jobs in the tourism sector, if not better. The various components of the tourism sector such as travel agencies, tour operation sector, hotels, resorts and other accommodation establishments, catering centres, airlines, etc. offers a lot of opportunities for women. Social inhibitions, lack of awareness, negative image of the job, lack of interaction of the business with the society, lack of skill development programmes, etc. constituted some issues why women did not have equal share as men in employment.

Also, it has to be pointed out that the issues are not there in all the industry units connected with tourism. The formal sector usually does not pose many issues for women, though the share of employment will be less. Many women employees are 
there, working in different tourism establishments who do not face any issue of sexual harassment or similar from the working environment. 'Tourism opens doors for women' was the theme for the United Nations. World Tourism Day last year, which like each year will be celebrated on $27^{\text {th }}$ September, the anniversary of the adoption of the original UNWTO statutes. By choosing this theme, World Tourism Organization urges the industry globally to enhance further the role of women. WTO plans to focus its attention on the role of gender in tourism and how to enhance it in tourism.

WTO chose this since the promotion of gender equality; empowerment of women and the elimination of gender disparity in education is the 3rd UN Millennium Development Goal. A campaign is being organized to address the important role tourism can play in creating opportunities for employment that will help eliminate poverty in local communities in developing countries around the world'.

A series of seminars, conferences and summits were organized last year to deal with the issue of women and tourism. A range of issues has been pointed out and the serious deliberations and the output of them were inspirational and it has been noted that the scenario is changing considerably.

Though WTO and many other international bodies highlight women's' achievements in the tourism sector, the sector is yet to be mature enough to provide equal opportunities and status for women with men.

A round table conference on "Do Women Really Benefit from Tourism" held recently at Trivandrum (India) alleged that though the international, national and state level policies on tourism are committed to women's empowerment, they rarely do anything beyond that to understand and evolve specific measures. The joint statement issued by the organizers, the Sakhi Resource Centre for Women (Kerala) and the Equations, and the Alternatives (Goa) and the Council for Social Justice and Peace (Goa) said that UNWTO should declare women's rights and empowerment as a move towards "opening the doors to a more just and equitable world for women and men".

As discussed above, tourism is still struggling to offer equality for women in employment. The selection of the theme "Tourism Opens Doors for women" by UNWTO needs appreciation; the efforts at the international level shouldn't be limited to it alone. We all are aware that the scenario would not change all of a sudden. Increased efforts are required in this aspect and it would more appropriate if it is led by World Tourism Organization. Extensive propaganda against inequality through various media would be needed. Women have to be empowered through education, orientation and more opportunities have to be provided. Tourism 
Authorities, Trade Associations, International Travel/Tourism Organizations have to take a lead role in giving more opportunities for women and to minimize gender divide and inequality and the related aspects.

The UNDP study suggests that multi-stakeholder collaborative efforts are needed for strengthening women's participation and to enhance women status in the tourism sector. Small and medium scale developments would certainly benefit the women community particularly in improving entrepreneurship. Micro credit programmes can be offered to women to have small investments by women in tourism. Awareness programmes on the opportunities, how to cope up with the difficult situations, how to have better employment, etc. are needed at this juncture. Strengthening community participation is an inevitable factor for aiming at strengthening women's participation in tourism. Educating women about their rights, roles, importance in the working situation in the industry and exposing them how to cope up with the male domination and female harassment by male counterparts in the working environment would be necessary in strengthening women's participation in the tourism sector.

As a solution to the issues in connection with the problems faced by women community in the case of employment in tourism, gender audits and gender budgeting can be considered as tools in mitigating the gender disparity. Proper research and data collection would be required to find out the actual share of women and the inherent issues. The authorities can come up with awareness creation programmes, training and management development programmes and similar initiatives to boost up increased women participation in the tourism sector. Promoting small and medium scale businesses would definitely help improving women entrepreneurship in tourism and consequently the employment share as well. The international campaign should be continued for a long term and trade associations have to come up with increased programmes to eliminate inequality for women in tourism. Most importantly ensuring community participation in tourism development, particularly women's participation in all aspects related planning, decision making, controlling, etc. by the governmental authorities, industries and others would definitely help to improve the situation tremendously.

\section{References}

- Cooper Chris, Fletcher Jon, Gilbert David and Swanhill Stephen, 1993, Tourism-principles and Practices, Pitman with EL/BS, London.

- Dutta. Mondira Dr (2000), Gendered tourism in India -Problems \& Prospects in the proceedings of the international conference and women on women's studies -Asian connection held at University of British Colombia.

- Equations, 1998, AN Letter, Equations, Bangalore. 
- Haladi A, Tourism's blind spot in Goa: women and gender issues http:// www.esocialsciences.com/data/eSSResearchPapers/eSSWPArticle200851410523.doc, data accessed on 12/07/08.

- Hemmati M, 2000, Women's Employment and Participation in Tourism, Sustainable Travel \& Tourism. pp17-20, 2000.

- International Labour Organisation, 1998. World Employment Report 1998-99. ILO: Geneva

- Rao, Nina, 'Women and Tourism', paper presented at a workshoporganized by Institute for Management in Government, Thiruvananthapuram, 21-23rd July, 1997.

- Sinclair, M.T. (ed.), 1998. Gender, Work and Tourism. London: Routledge.

- Singh, Sunita- Sengupta (2003), women leadership in Originations (socio-cultural Determinants) Gyan Publishing House, New Delhi-110002.pp 17-18.

- WTO world tourism barometer, (2005), World tourism organization, Spain.

- United Nations Development Programme (UNDP), 1995. Human Development Report: Gender and Human Development. New York: Oxford University Press. 